\title{
Structural Identification of Oxidized Acyl-Phosphatidylcholines That Induce Platelet Activation
}

\author{
Matthias S. Göpfert ${ }^{a}$ Frank Siedler $^{c}$ Wolfgang Siess ${ }^{a} \quad$ Alois Sellmayer ${ }^{a}$ b \\ a Institut für Prophylaxe und Epidemiologie der Kreislaufkrankheiten und b ${ }^{b}$ Medizinische Poliklinik, Klinikum der \\ Universität München, München, und 'Max-Planck-Institut für Biochemie, Abteilung Membranbiochemie, \\ Martinsried, Deutschland
}

\section{Key Words \\ Lipid oxidation · Low-density lipoprotein • \\ Phospholipids · Platelet-activating factor $\cdot$ Platelets}

\begin{abstract}
Oxidation of low-density lipoprotein (LDL) generates proinflammatory and prothrombotic mediators that may play a crucial role in cardiovascular and inflammatory diseases. In order to study platelet-activating components of oxidized LDL 1-stearoyl-2-arachidonoyl-sn-glycero-3-phosphocholine, a representative of the major phospholipid species in LDL, the 1-acyl-phosphatidylcholines (PC), was oxidized by $\mathrm{CuCl}_{2}$ and $\mathrm{H}_{2} \mathrm{O}_{2}$. After separation by high-performance liquid chromatography, three compounds were detected which induced platelet shape change at low micromolar concentrations. Platelet activation by these compounds was distinct from the pathways stimulated by platelet-activating factor, lysophosphatidic acid, lyso-PC and thromboxane $A_{2}$, as evidenced by the use of specific receptor antagonists. Further analyses of the oxidized phospholipids by electrospray ionization mass spectrometry structurally iden-
\end{abstract}

\section{KARGER}

Fax +41613061234

E-Mail karger@karger.ch

www.karger.com (c) 2005 S. Karger AG, Basel

1018-1172/05/0422-0120\$22.00/0

Accessible online at: www. karger.com/jvr tified them as 1-stearoyl-2-azelaoyl-sn-glycero-3-phosphocholine (m/z 694; SAzPC), 1-stearoyl-2-glutaroyl-snglycero-3-phosphocholine (m/z 638; SGPC), and 1-stearoyl-2-(5-oxovaleroyl)-sn-glycero-3-phosphocholine $(\mathrm{m} / \mathrm{z}$ 622 ; SOVPC). These observations demonstrate that novel 1-acyl-PC which had previously been found to stimulate interaction of monocytes with endothelial cells also induce platelet activation, a central step in acute thrombogenic and atherogenic processes.

Copyright $@ 2005$ S. Karger AG, Basel

\section{Introduction}

Growing evidence indicates that oxidation of low-density lipoproteins (LDL) plays an important role in atherogenesis by stimulating proinflammatory processes in the cells of the vascular wall [1]. In addition, oxidized LDL also induces platelet activation, as reflected by platelet shape change [2], increases in free cytosolic calcium levels [3] and platelet aggregation [2, 4]. Activation of platelets by oxidized LDL is of pathophysiological significance. Firstly, upon rupture of soft lipid-rich plaques, oxidized 
LDL particles are exposed to circulating platelets, contributing to the formation of intravascular thrombi responsible for acute ischemic syndromes. Indeed, experimental evidence indicates that the lipid-rich atheromatous core and not the exposed collagen is thrombogenic [5]. Secondly, oxidatively modified LDL is present in the circulation [6], and its plasma levels are elevated in patients with coronary artery disease [7]. Platelet activation by circulating oxidized LDL might be one reason for the platelet hyperreactivity often observed in these patients [8].

In vitro, oxidation of LDL results in the modification of phospholipids, mainly of phosphatidylcholine (PC), the major phospholipid in LDL, and oxycholesterol [9]. Primarily, polyunsatured fatty acids in the $s n-2$ position of the phospholipid are oxidized to hydroperoxides and subsequently undergo fragmentation to aldehydes, which can further modify amino groups in proteins and phospholipids. Interestingly, oxidation of LDL predominantly modifies arachidonic acid and much less linoleic acid contained in phospholipids [10]. Although several phospholipids which stimulate monocytes and endothelial cells have been identified in oxidized LDL [11-13], structural characterization of platelet-activating molecules is limited. To this end, lysophosphatidic acid (LPA) has been identified as the main platelet-activating lipid in mildly oxidized LDL and atherosclerotic plaques [14]. Very recently, a platelet-activating factor (PAF) analogue, 1-Ohexadecyl-2-(5-oxovaleroyl)-sn-glycero-phosphocholine, has been identified in human atheroma that induced aggregation of rabbit platelets through activation of the PAF receptor, whereas its 1-acyl-analogue, 1-palmitoyl-2(5-oxovaleroyl)-sn-glycero-phosphocholine, stimulated in rabbits platelet shape change, which was independent from the activation of the PAF receptor [15]. Furthermore, oxidation of $\mathrm{PC}$ has been found to result in the formation of PAF-like compounds [16], which have been partially characterized as sn-2-butanoyl and butenoyl (C4)-PAF analogues [17]. Additional oxidized PC derivatives have been characterized and found to stimulate monocytes and endothelial cells. These substances are formed from the predominant PC, ester-linked 1-acyl-2acyl-sn-glycero-phosphocholine, and the minor group of PC, ether-linked 1-alkyl-2-acyl-sn-glycero-phosphocholine. Oxidation of the latter revealed formation of 1alkyl-2-azelaoyl-sn-glycero-phosphocholine that activated the peroxisome proliferator-activated receptor- $\gamma$ in monocytes [18]. Furthermore, non-PAF-like phospholipid oxidation products of 1-acyl-PC have been characterized from minimally modified LDL and from human and rabbit atherosclerotic lesions as 1-palmitoyl-2-glutaroyl-sn- glycero-phosphocholine and 1-palmitoyl-2-epoxyisoprostane-sn-glycero-phosphocholine $[19,20]$. These substances stimulate endothelial binding of monocytes and neutrophils [21] and the expression of tissue factor in endothelial cells [22] through signaling pathways other than the PAF receptor [23]. Furthermore, they may also mitigate endotoxin shock in vivo [24].

This study was designed to assess whether oxidation products of authentic 1-acyl-2-acyl-sn-glycero-phosphocholine have platelet-activating effects and to structurally identify these compounds. After oxidation of 1-stearoyl2-arachidonoyl-sn-glycero-phosphocholine (SAPC) with $\mathrm{CuCl}_{2}$ and $\mathrm{H}_{2} \mathrm{O}_{2}$, three compounds were found to stimulate shape change in human platelets, which was independent from the activation of the receptors for PAF, LPA or thromboxane $\mathrm{A}_{2}\left(\mathrm{TxA}_{2}\right)$. Electrospray ionization-mass spectrometry (ESI-MS) revealed that these compounds were 1-stearoyl-2-azelaoyl-sn-glycero-3-phosphocholine (m/z 694; SAzPC), 1-stearoyl-2-glutaroyl-sn-glycero-3phosphocholine (m/z 638; SGPC), and 1-stearoyl-2(5-oxovaleroyl)-sn-glycero-3-phosphocholine (m/z 622; SOVPC).

\section{Materials and Methods}

\section{Materials}

Synthetic 1-stearoyl-2-[ $\left.{ }^{14} \mathrm{C}_{1}\right]$-arachidonoyl-sn-glycero-3-phosphocholine (specific activity $54 \mathrm{mCi} / \mathrm{mmol}$ ) was from Amersham (Braunschweig, Germany). WEB 2086 was a kind gift from Dr. Düttmann (Boehringer, Ingelheim, Germany) and $N$-palmitoyl tyrosine phosphoric acid NPTyrPA was a kind gift from Dr. Bittman (Flushing, N.Y., USA). SQ 29,548 and U46619 were obtained from Alexis (Grünberg, Germany) and Calbiochem (Darmstadt, Germany), respectively. All reagents used for phospholipid extraction, derivatization and chromatography were of analytical grade and purchased from Baker (Griesheim, Germany) or Merck (Darmstadt, Germany). Synthetic 1-stearoyl-2-arachidonoyl-sn-glycero-3-phosphocholine as well as all other reagents were from Sigma (Deisenhofen, Germany).

\section{Free Radical Oxidation and Extraction of SAPC}

Free radical oxidation of SAPC was performed as described by Harrison and Murphy [25], with slight modifications. In brief, $7.2 \mathrm{mg}$ of SAPC were placed in a glass tube and $0.5 \mu \mathrm{Ci}$ of 1-stearoyl-2$\left[{ }^{14} \mathrm{C}_{1}\right]$ arachidonoyl-sn-glycero-3-phosphocholine was added as indicated. After evaporation of the solvent under a stream of nitrogen, SAPC was immediately resuspended in $50 \mu 1$ of $98 \%$ ethanol followed by addition of $4.8 \mathrm{ml}$ of $50 \mathrm{~m} M$ Trizma buffer, $\mathrm{pH} 7.35$. To optimize the suspension, the solution was placed in an ultrasonic water bath at full power for $2 \mathrm{~min}$. Thereafter, SAPC was oxidized

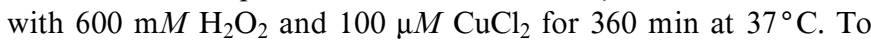
determine the time course of oxidative modification of SAPC, aliquots were taken at the time points indicated. Oxidation was terminated by the addition of 1,000 units catalase for $10 \mathrm{~min}$ at $37^{\circ} \mathrm{C}$. Lipids were then extracted twice with $800 \mu l$ of water-saturated 
1-butanol and were dried under vacuum and stored at $-80^{\circ} \mathrm{C}$ until further analyses.

\section{Reverse-Phase High-Performance Liquid Chromatography}

RP-HPLC was performed with a $\mathrm{C}_{18}$ column (Nucleosil 100, $250 \times 4.6 \mathrm{~mm}$, Macherey \& Nagel, Düren, Germany) and a Supelcoguard LC-18-DB precolumn (Supelco, Germany). Phospholipids were eluted with a two-solvent gradient system starting with $80 \%$ $\mathrm{MeOH}, 20 \%$ water containing $0.5 \mathrm{~m} M$ ammonium acetate for 25 $\min$. Thereafter, the solvent changed linearly over $50 \mathrm{~min}$ to $100 \%$ $\mathrm{MeOH}$ containing $0.5 \mathrm{~m} M$ ammonium acetate and continued with this solvent for another $25 \mathrm{~min}$. The flow rate was 1.5 or $2.0 \mathrm{ml} / \mathrm{min}$. Column temperature was held constant at $22^{\circ} \mathrm{C}$ with a Gynkotek STH 585 column conditioner (Gynkotek, Germering, Germany). UV absorbance was detected with a diode array detector (Gynkotek UVD 320S) set at 205, 235, 242 and $270 \mathrm{~nm}$. The eluent was collected in 1-min fractions. Samples containing $\left[{ }^{14} \mathrm{C}\right]$-labeled phospholipids were counted in a liquid scintillation counter (Wallac 1410; Pharmacia, Germany). Non-radioactive phospholipids were dried under vacuum and stored at $-80^{\circ} \mathrm{C}$ until further analyses.

\section{Electrospray Ionization Mass Spectrometry}

ESI-MS and ESI-MS/MS spectra were measured using an Applied Biosystems API300 triple quadrupole mass spectrometer (Applied Biosystems, Weiterstadt, Germany) equipped with an in-housebuilt nanospray source. For full scan spectra of the whole oxidation mixture, the dried sample was diluted with $80 \% \mathrm{MeOH}$ in $0.5 \mathrm{mM}$ ammonium acetate buffer and approximately $3 \mu \mathrm{l}$ were transferred to an in-house-pulled nanospray capillary tube and mounted in the source. Usually, a small pressure of compressed air was applied to the capillary tube to initiate the spray. The high voltage applied to the capillary varied from 800 to $1,000 \mathrm{~V}$ in the positive mode and from -600 to $-800 \mathrm{~V}$ in the negative mode. The orifice voltage was optimized for each experiment. Compressed nitrogen 5.0 (Linde, Pullach, Germany) was used as curtain and as collision gas in MS/MS experiments. The scan range was $500-1,000 \mathrm{~m} / \mathrm{z}(2 \mathrm{~s} / \mathrm{scan})$ for the ESI-MS spectra and $30 \mathrm{~m} / \mathrm{z}$ units above the $\mathrm{m} / \mathrm{z}$ value of the parent ion $(2 \mathrm{~s} / \mathrm{scan})$ for the ESI-MS/MS spectra.

\section{Derivatization of Phospholipids}

After purification and separation by RP-HPLC, $250 \mu \mathrm{g}$ of the oxidation product with $\mathrm{m} / \mathrm{z} 622$ was dried under argon, and $100 \mu \mathrm{l}$ of $0.92 \mathrm{~m} M$ methoxyamine hydrochloride in phosphate-buffered saline was added. The solution was mixed thoroughly and incubated for 45 min at room temperature. Thereafter, lipids were extracted with $\mathrm{CHCl}_{3} / \mathrm{MeOH}$ and analyzed by ESI-MS or ESI-MS/MS. In parallel, $250 \mu \mathrm{g}$ of each of the oxidation products with $\mathrm{m} / \mathrm{z} 694$ and 638 were dried under argon, and $50 \mu \mathrm{l}$ of $20 \%(\mathrm{w} / \mathrm{w}) \mathrm{N}, \mathrm{N}$-diisopropylethylamine in acetonitrile as well as $50 \mu 1$ of $10 \%(\mathrm{w} / \mathrm{w})$ pentafluorobenzyl bromide in acetonitrile were added, respectively. The solutions were mixed thoroughly and incubated for $45 \mathrm{~min}$ at room temperature. Lipids were extracted with $\mathrm{CHCl}_{3} / \mathrm{MeOH}$ and analyzed by ESI-MS or ESI-MS/MS.

Platelet Isolation and Determination of Platelet Shape Change

Blood was taken from healthy volunteers and anticoagulated with $10 \%(\mathrm{v} / \mathrm{v})$ citrate. After centrifugation at $180 \mathrm{~g}$, platelet-rich plasma was separated, acetylsalicylic acid $(1 \mathrm{~m} M)$ was added and platelets were further isolated and washed as described [26]. Platelets were resuspended at a concentration of $0.4 \times 10^{6}$ platelets per milliliter in buffer C (HEPES $20 \mathrm{~m} M, \mathrm{NaCl} 138 \mathrm{~m} M, \mathrm{KCl} 2.9 \mathrm{~m} M, \mathrm{MgCl}_{2} 1 \mathrm{~m} M$, $\mathrm{NaH}_{2} \mathrm{PO}_{4} 0.36 \mathrm{~m} M, 0.6 \mathrm{ADPase}$ units/ml apyrase, $\mathrm{pH}$ 7.4) and 0.16 $\times 10^{6}$ platelets were transferred into aggregometer cuvettes and incubated at $37^{\circ} \mathrm{C}$ while stirring at $1,100 \mathrm{rpm}$ in an aggregometer. After 5 min, oxidation products that were resuspended at a concentration of $4 \mathrm{~m} M$ in ethanol/distilled water $(50 / 50 ; \mathrm{v} / \mathrm{v})$ or the agonists indicated were added. Shape change was measured by the decrease in light transmission [14]. Receptor antagonists were added $1 \mathrm{~min}$ prior to the oxidation products or the specific platelet stimuli.

\section{Determination of Free Cytosolic Calcium Concentrations in}

Platelets

Human platelets were prepared as described above without prior treatment with acetylsalicylic acid. Determination of free cytosolic calcium was performed as described previously [3]. In brief, platelets $\left(1 \times 10^{9} / \mathrm{ml}\right)$ were loaded with the calcium-sensitive dye Fura-2/AM $(4 \mu M)$ and incubated in the presence of bovine albumin $(1 \mathrm{mg} / \mathrm{ml})$ for $1 \mathrm{~h}$ at $37^{\circ} \mathrm{C}$ in buffer $\mathrm{C}$, washed with buffer $\mathrm{C}$ and resuspended in buffer $\mathrm{C}$ at a concentration of $1 \times 10^{9} / \mathrm{ml}$ in the presence of bovine albumin $(1 \mathrm{mg} / \mathrm{ml})$. Before measurement, platelets were diluted to $0.2 \times 10^{9} / \mathrm{ml}$ with buffer $\mathrm{C}$ and incubated for $5 \mathrm{~min}$ at $37^{\circ} \mathrm{C}$ before $\mathrm{CaCl}_{2}(1 \mathrm{~m} M)$ was added. Oxidation products or the agonists indicated were added and fluorescence was measured using excitation wavelengths of 340 and $380 \mathrm{~nm}$ and an emission wavelength of $510 \mathrm{~nm}$. Free cytosolic calcium concentrations were calculated by the modified Lambert-Beer formula as described previously [27].

\section{Results}

\section{Separation of Oxidized SAPC by RP-HPLC}

Oxidized SAPC was fully separated from unoxidized SAPC by RP-HPLC. Determination of the time course of oxidation revealed that SAPC was almost completely oxidized to more polar compounds within $360 \mathrm{~min}$ (fig. 1A). Three major compounds were formed (fig. 1B) which eluted at about 9 min (compound 1), 16 min (compound 2) and $36 \mathrm{~min}$ (compound 3 ) after RP-HPLC. The UV absorbance of compounds 1-3 was only weak at $205 \mathrm{~nm}$ and virtually undetectable at 235, 242 or $270 \mathrm{~nm}$, indicating that these compounds did not have the configuration of conjugated dienes or trienes. Compound 3 was the most prominent oxidation product, and was about twice as much as compounds 1 and 2. To assess the biological activity and the molecular structure of these compounds, non-radioactive oxidation products of SAPC were collected at the characteristic retention times and used for further studies.

\section{Platelet Shape Change and Free Cytosolic Calcium after Exposure to Oxidized SAPC}

Addition of either one of the three compounds at concentrations of 2.5 to $10 \mu M$ to washed human platelets pretreated with acetylsalicylic acid resulted in the induc- 
Fig. 1. RP-HPLC chromatogram showing the time course of SAPC oxidation. SAPC (1.6 mg non-radioactive SAPC plus $0.5 \mu \mathrm{Ci}$ $\left.\left[{ }^{14} \mathrm{C}\right]-\mathrm{SAPC}\right)$ was oxidized by $\mathrm{CuCl}_{2}$ and $\mathrm{H}_{2} \mathrm{O}_{2}$ for the time periods indicated (A) or for $360 \mathrm{~min}$ (B), separated by RP-HPLC as detailed in the 'Experimental Procedures' and collected in 1-min intervals. Oxidation products were detected by liquid scintillation. Note that the flow rate was $2.0 \mathrm{ml} / \mathrm{min}$ (A) and $1.5 \mathrm{ml}$ for better separation (B).
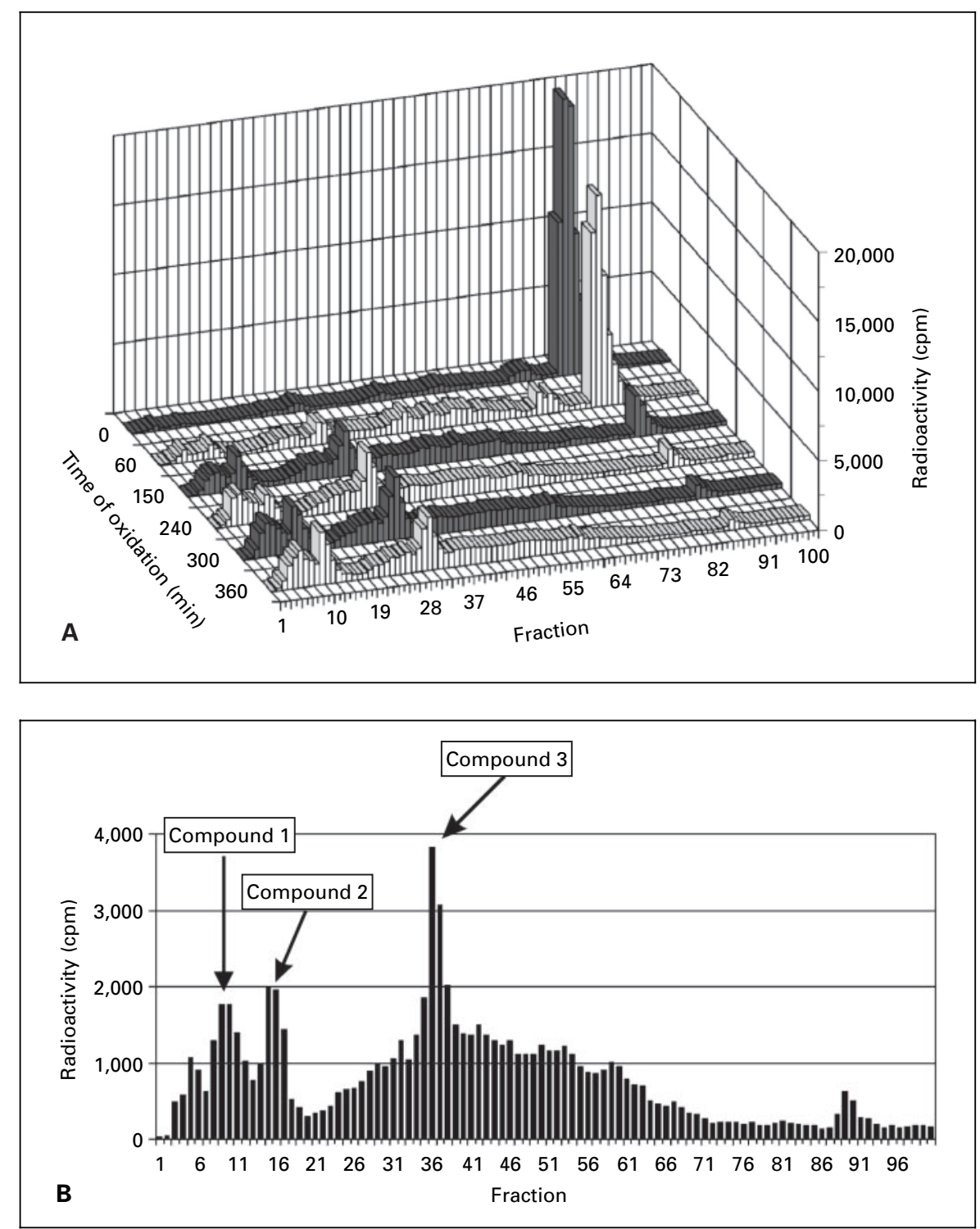

tion of shape change (fig. 2A, B). The stimulatory activity of each of the three compounds at a concentration of $10 \mu M$ was almost equal to the effect of $1 \mu M$ ADP.

Unoxidized SAPC $(20 \mu M)$ did not stimulate platelet shape change (fig. 2A). To assess the possible receptors activated, receptor antagonists for phospholipid mediators and eicosanoids known to activate platelets were used. Inhibition of the PAF receptor by WEB 2086 $(1 \mu M)$ [28], the LPA receptor by $N$-palmitoyl tyrosinephosphoric acid (NPTyrPA, $1.2 \mu M$ ) [29] or the TxA 2 receptor by SQ 29,548 $(2.5 \mu M)$ [30] did not affect shape change induced by compound 1 (fig. $2 \mathrm{~B}$ ) or any one of the other two compounds (data not shown). In contrast, shape change was inhibited by WEB 2086, SQ 29,548 and NPTyrPA in response to stimulation with the receptor agonists PAF, U46619 and LPA, respectively (fig. 2C). These observations indicated that the oxidation products activate platelets by receptors distinct from PAF, LPA and $\mathrm{TxA}_{2}$.

In contrast to stimulation with PAF, none of the three compounds increased free cytosolic calcium concentrations $\left(\left[\mathrm{Ca}^{2+}\right]_{\mathrm{i}}\right)$, determined by fluorometric measurements of Fura-2-loaded platelets. As shown in figure 3, stimulation with compound $1(10 \mu M)$ did not affect $\left[\mathrm{Ca}^{2+}\right]_{\mathrm{i}}$, 
Fig. 2. Induction of platelet shape change by the three major oxidation products of SAPC. A Suspensions of washed human platelets were stimulated by increasing concentrations of compound 1 (upper part) or with compounds 2 or 3 (each $10 \mu M$ ), ADP $(1 \mu M)$ or unoxidized SAPC $(20 \mu M$; lower part). B Suspensions of washed human platelets were preincubated with WEB 2086 $(1.0 \mu M)$ or SQ 29,548 $(2.5 \mu M)$ for $1 \mathrm{~min}$ or NPTyrPA $(1.2 \mu M)$ for 15 min and stimulated with compound $1(10 \mu M)$. C Suspensions of washed human platelets were preincubated with WEB $2086(1.0 \mu M)$, SQ $29,548(2.5 \mu M)$ and NPTyrPA $(1.2 \mu M)$ and stimulated with PAF $(1.0 \mu M), \mathrm{U} 46619$ $(50 \mathrm{n} M)$ and LPA (50 $\mathrm{n} M)$, respectively. Shape change was determined in an aggregometer. The decrease in light transmission together with the disappearance of rapid oscillations is indicative of shape change. Tracings shown are representative of at least 5 separate experiments for each agonist.
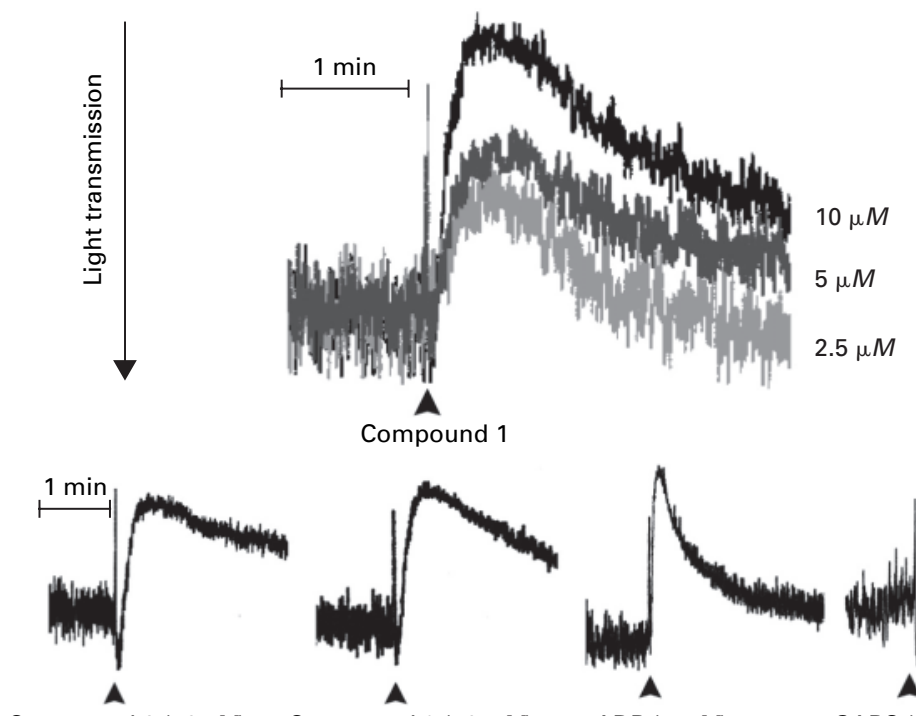

$\operatorname{ADP}(1 \mu M)$

A

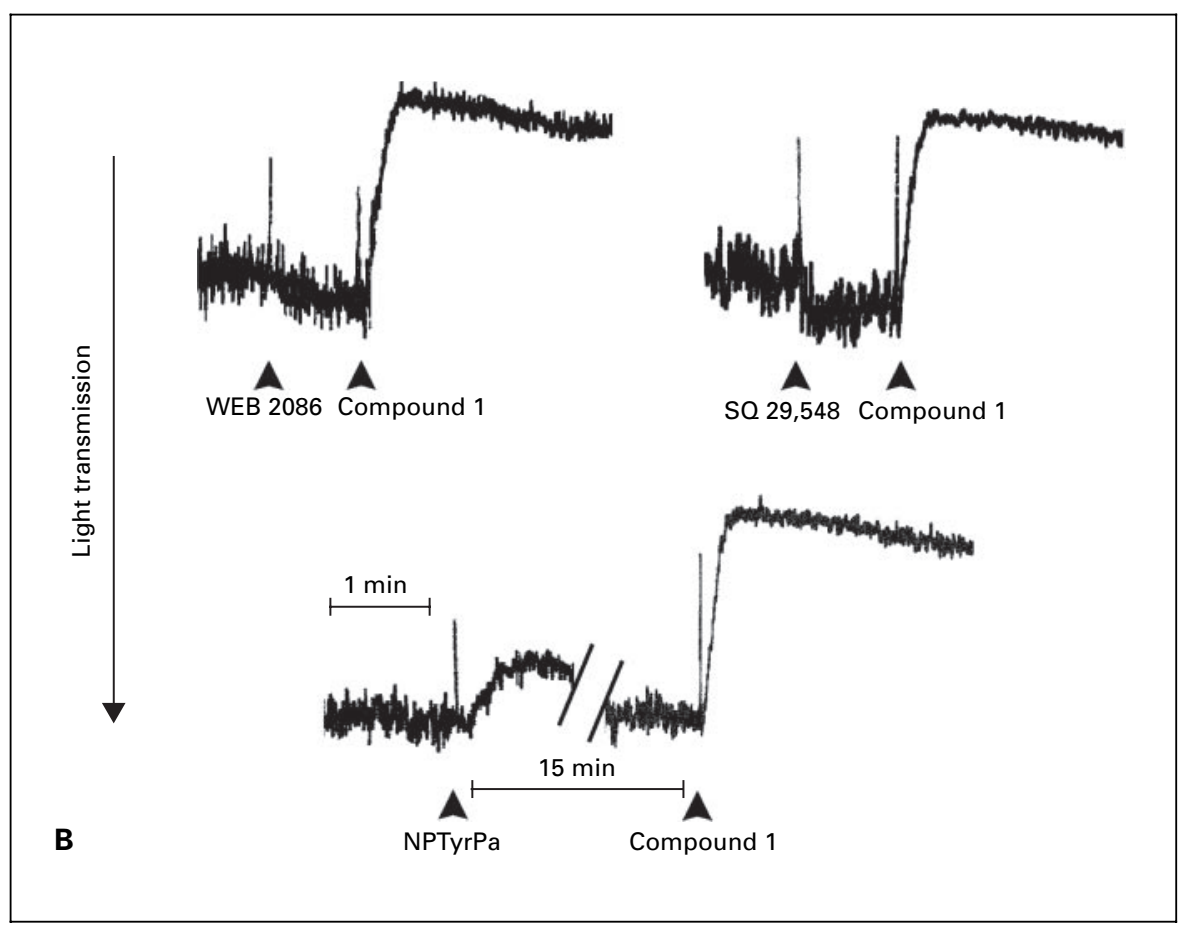

whereas subsequent addition of PAF $(2.5 \mu M)$ to the same platelet preparation induced a characteristic rise in $\left[\mathrm{Ca}^{2+}\right]_{i}$, indicating that signalling of compound 1 differed from PAF. The same observations were made with the other two compounds (data not shown).

\section{Purity Control of Purchased SAPC}

To exclude contamination of the purchased SAPC, a positive ion mode ESI-MS analysis was performed. There was only one major peak detectable at $\mathrm{m} / \mathrm{z} 811$ with represents SAPC (fig. 4). The small peak at $\mathrm{m} / \mathrm{z} 832.9$ represents a sodium adduct during ESI-MS analysis. 


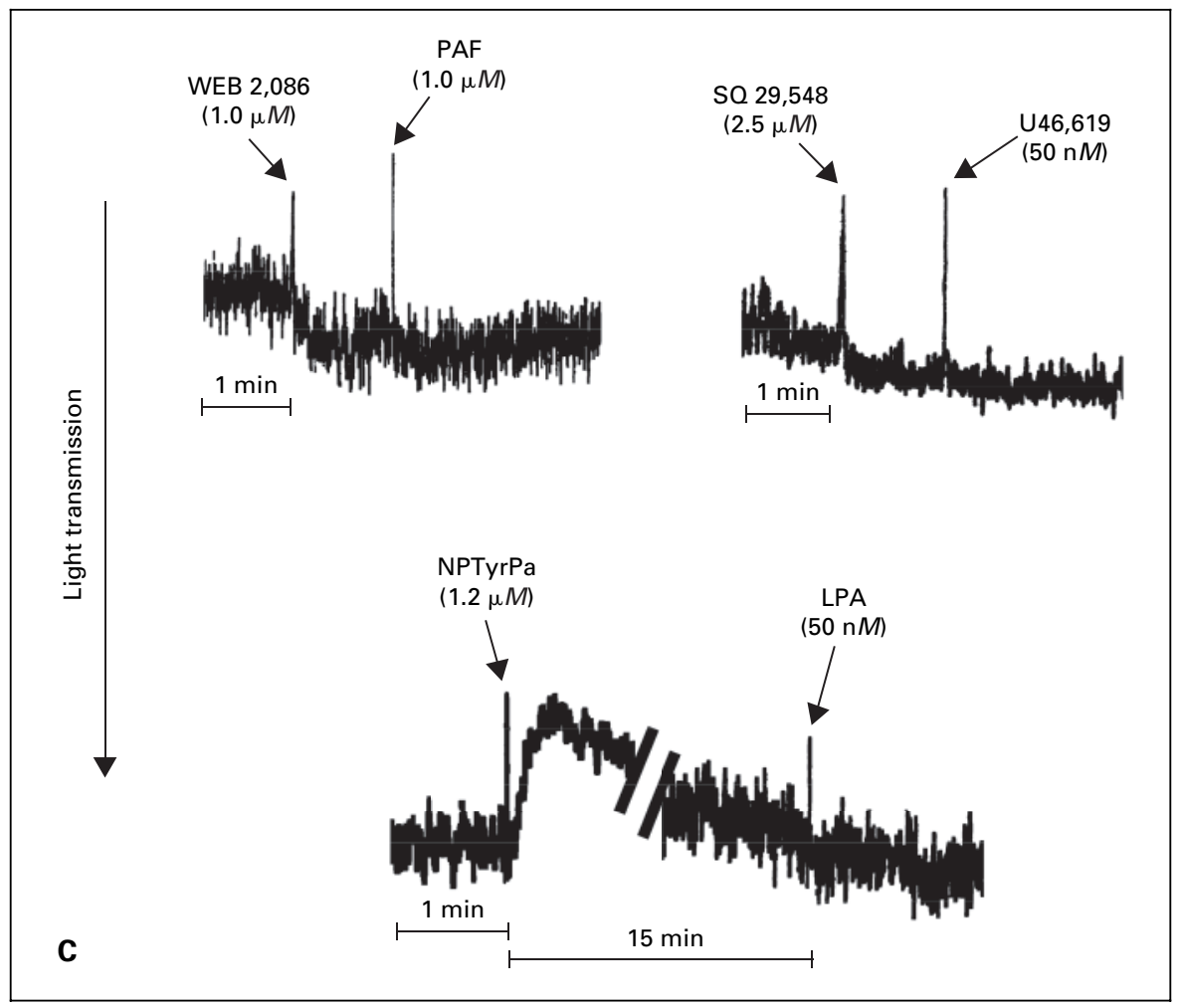

\section{Structural Analysis of Compound 1}

Nano-ESI-MS analysis in the positive ion mode of RPHPLC-purified compound 1 revealed a major peak at $\mathrm{m} / \mathrm{z}$ 694 (fig. 5A). The compound at m/z 694 would be compatible with an oxidatively modified form of SAPC possessing a 9-carbon moiety with a terminal carboxylic acid, azelaic acid, at the $s n-2$ position and unmodified moieties at the $s n-1$ (stearic acid) and $s n-3$ (phosphocholine) positions. This molecule, 1-stearoyl-2-azelaoyl-sn-glycero-3phosphocholine, would produce a $(\mathrm{M}+\mathrm{H})^{+}$ion at $\mathrm{m} / \mathrm{z} 694$. To prove this assumption, compound 1 was derivatized with pentafluorobenzyl bromide which is used to derivatize carboxylic acids and would add a pentafluorobenzyl group (180 Da) to the 9-carbon group at the $s n$-2 position. After treatment, ESI-MS analyses showed a reduced amount of the compound at $\mathrm{m} / \mathrm{z} 694$, and a major compound at $\mathrm{m} / \mathrm{z} 874$ becomes detectable, which was not present before (fig. 5B).

The structural identity of compound 1 was further confirmed by ESI-MS/MS analyses. In the positive ion mode, the product ion scan for $(\mathrm{M}+\mathrm{H})^{+}$at $\mathrm{m} / \mathrm{z} 694$ showed the ion pattern $\mathrm{m} / \mathrm{z} 184,104$ and 86 , which is typical for lipids containing phosphocholine (data not shown) [36].

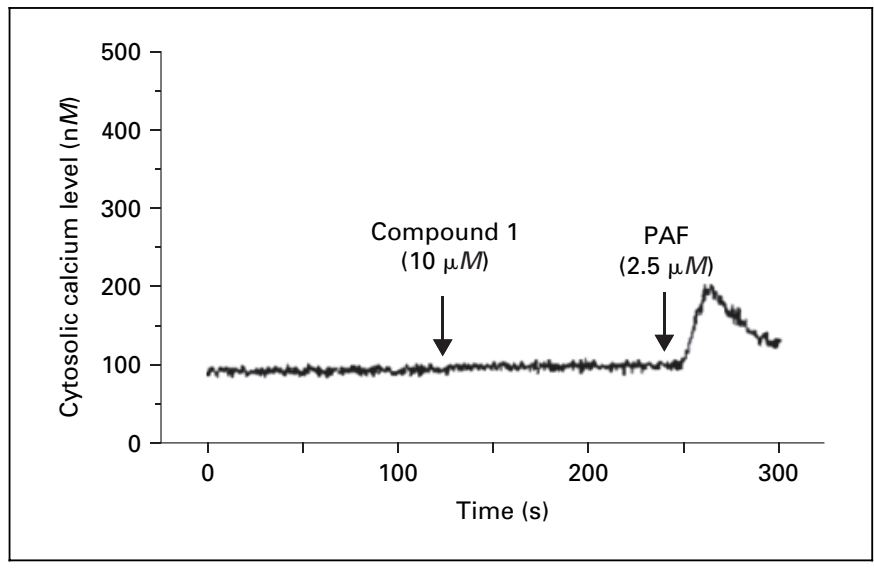

Fig. 3. Effects of the three major oxidation products on the release of intracellular calcium in platelets. A suspension of washed human platelets was loaded with Fura-2/AM and stimulated with compound $1(10 \mu M)$ or with PAF $(2.5 \mu M)$. Fluorescence was measured using excitation wavelengths of 340 and $380 \mathrm{~nm}$ and an emission wavelength of $510 \mathrm{~nm}$. Tracings shown are representative of 3 separate experiments. Tracings for compounds 2 or 3 did not differ from the tracing shown for compound 1 . 
Fig. 4. ESI-MS control of SAPC purity. To exclude contamination of the non-oxidized SAPC $^{+}$ion, ESI-MS analysis was performed. There were no contaminations with other substances, while there was only one relevant peak at $\mathrm{m} / \mathrm{z} 811$ detectable. The small peak at $832.9 \mathrm{~m} / \mathrm{z}$ represents a sodium adduct during ESI-MS measurement. The molecular structure of SAPC is also presented.

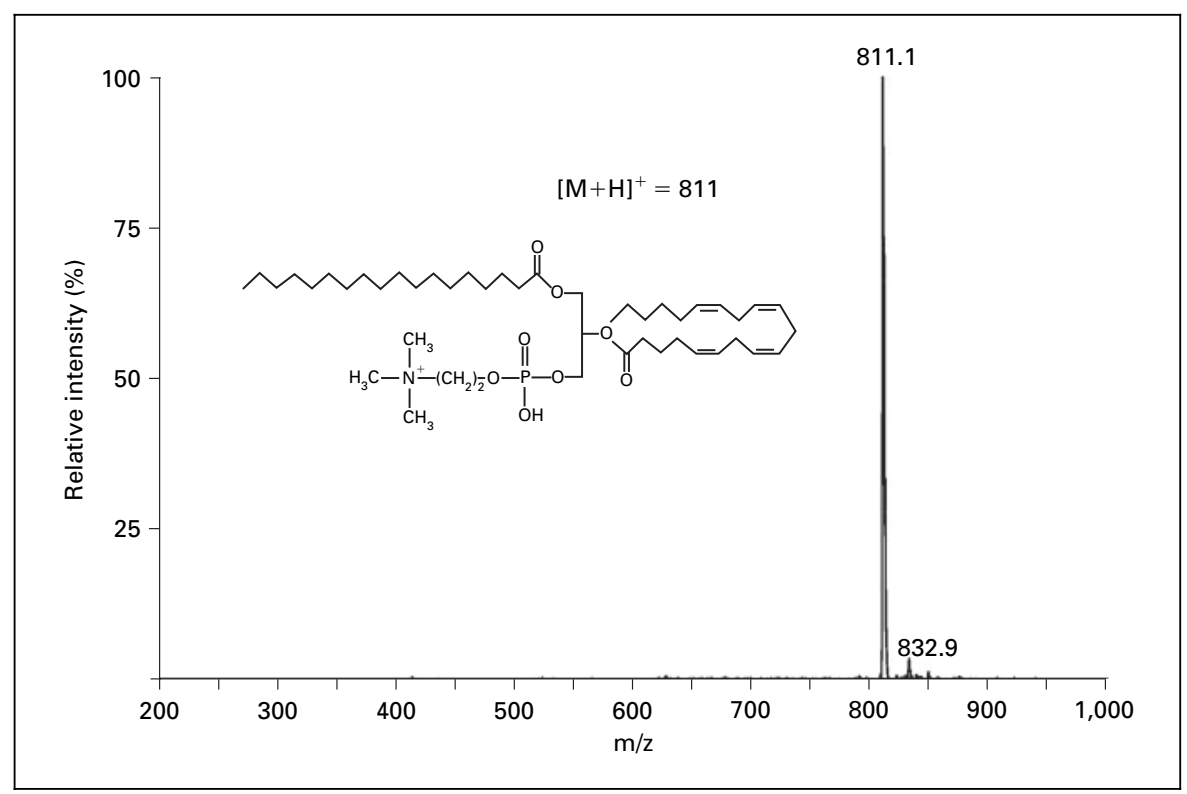

ESI-MS analysis in the negative ion mode revealed the major peak as expected for $(\mathrm{M}-\mathrm{H})^{-}$at $\mathrm{m} / \mathrm{z}$ 692. MS/MS studies on this parent ion produced signals at $\mathrm{m} / \mathrm{z} 633$, 508, 283, 201 and 169 (fig. 5C) consistent with the parent ion after a loss of trimethylamine (633), the unmodified stearoyl moiety (283) and the claimed azelaoyl moiety (169). Peaks at m/z 508 and 201 are the consequence of the well-known phenomenon of a methyl shift from the choline moiety to terminal carboxylic groups in the $s n-2$ position under fragmentation conditions [31] (see inset of fig. 5C for structural details). From these observations, we conclude that compound 1 is 1-stearoyl-2-azelaoyl-snglycero-3-phosphocholine (SAzPC).

\section{Structural Analysis of Compound 2}

Nano-ESI-MS analyses in the positive ion mode of RPHPLC-purified compound 2 revealed a major peak at $\mathrm{m} / \mathrm{z}$ 638 (fig. 6). This would be compatible with an oxidatively more shortened version of compound 1, possessing a glutaryl moiety in the $s n-2$ position instead of the azelaoyl. This molecule, 1-stearoyl-2-glutaroyl-sn-glycero-3-phosphocholine, produced a $(\mathrm{M}+\mathrm{H})^{+}$ion at $\mathrm{m} / \mathrm{z} 638$. To prove the structural identity, the same set of experiments was performed on compound 2 as on compound 1 (data not shown). From these observations, we conclude that compound 2 is 1-stearoyl-2-glutaroyl-sn-glycero-3-phosphocholine (SGPC).

\section{Structural Analysis of Compound 3}

Nano-ESI-MS analyses in the positive ion mode of RPHPLC-purified compound 3 revealed a major peak at $\mathrm{m} / \mathrm{z}$ 622 (fig. 7), which suggests the molecule to be the aldehyde analogue of compound 2, thus having 5-oxovaleric acid esterified at the $s n-2$ position. A specific derivatization method was chosen to prove the presence of a terminal aldehyde group. Positive ESI-MS/MS experiments showed further evidence for its chemical structure (data not shown).

From these observations, we conclude that compound 3 is 1-stearoyl-2-(5-oxovaleroyl)-sn-glycero-3-phosphocholine (SOVPC).

Fig. 5. Identification of compound 1 (m/z 694) as 1-stearoyl-2-azelaoyl-sn-glycero-3-phosphocholine by ESI-MS and ESI-MS/MS. Oxidized SAPC (1.6 mg) was separated by RP-HPLC. The fraction containing compound 1 was dried and dissolved in $80 \% \mathrm{MeOH}$ in $0.5 \mathrm{~m} M$ ammonium acetate. Analysis by positive ion ESI-MS followed either directly (A) or after treatment with pentafluorobenzyl bromide (B). Negative ion ESI-MS/MS was performed on the parent ion at $\mathrm{m} / \mathrm{z} 692$ without prior derivatization (C). Proposed molecular structures and fragmentation patterns are also presented.

(For figure 5C see page 128.) 

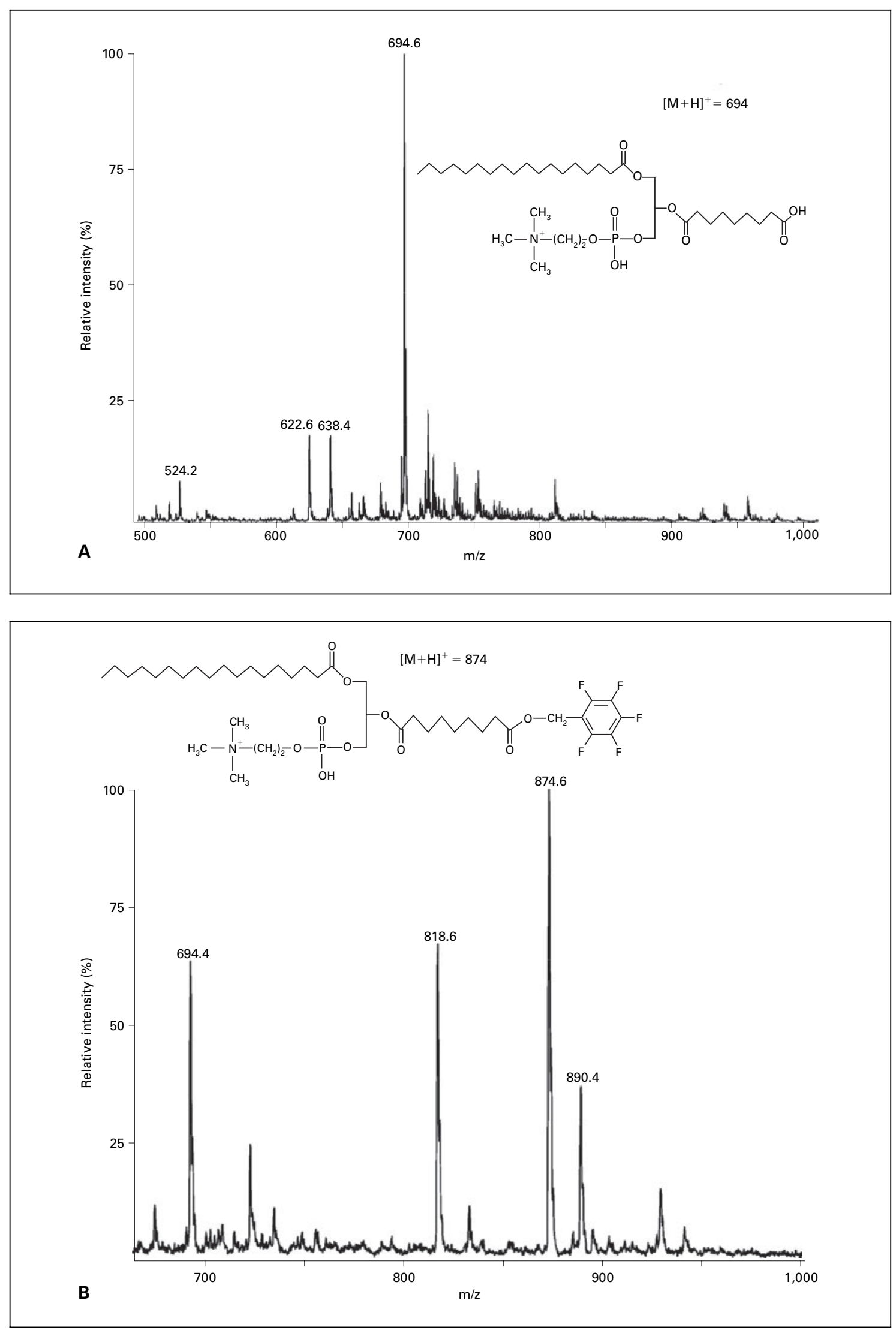


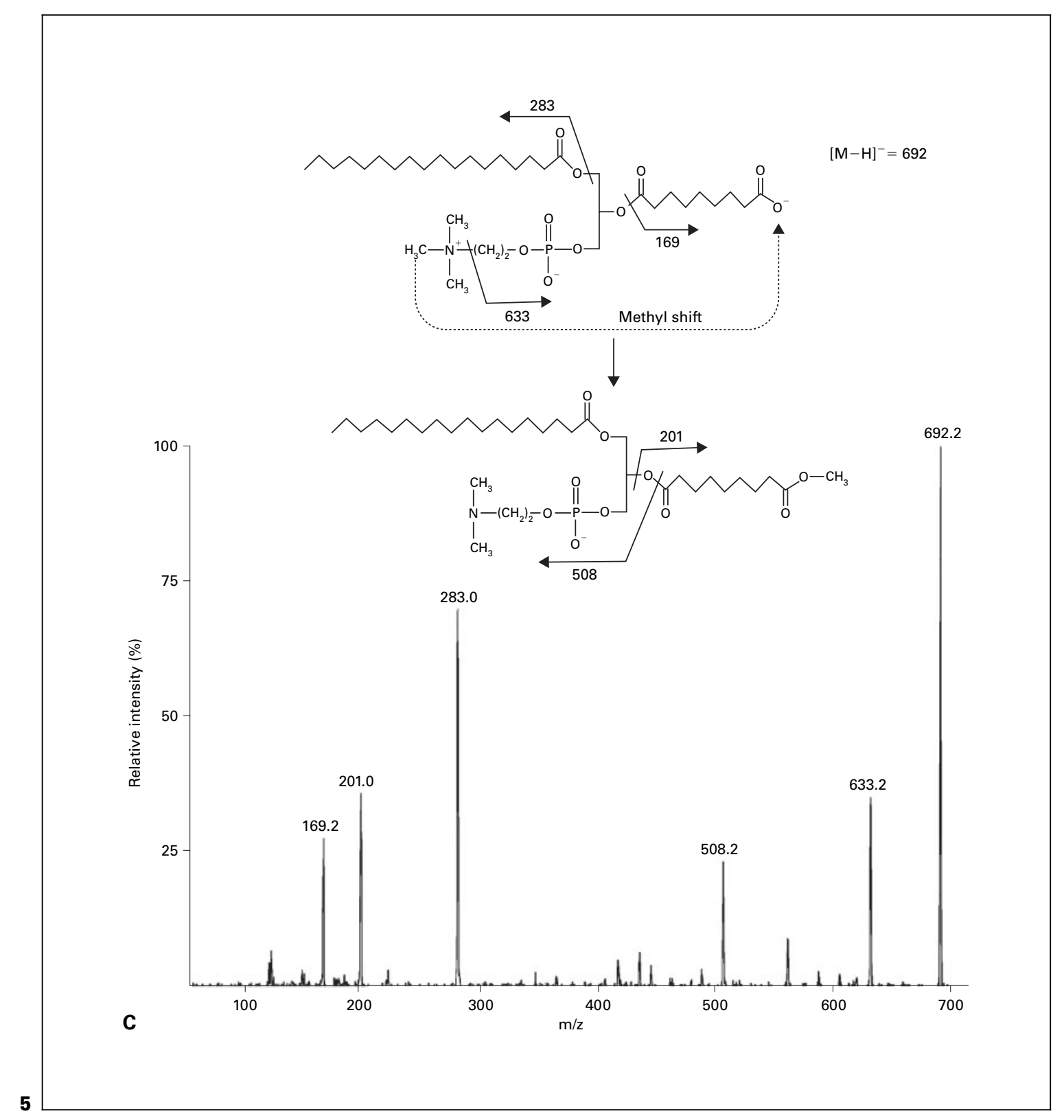

(For legend see page 126.)

Fig. 6. Identification of compound $2(\mathrm{~m} / \mathrm{z} 638)$ as 1-stearoyl-2-glutaryl-sn-glycero-3-phosphocholine by ESI-MS. Oxidized SAPC $(1.6 \mathrm{mg})$ was separated by RP-HPLC. The fraction containing compound 2 was dried and dissolved in $80 \% \mathrm{MeOH}$ in $0.5 \mathrm{mM}$ ammonium acetate. Analysis by positive ion ESI-MS followed directly. The molecular structure of compound 2 is also presented.

Fig. 7. Identification of compound 3 (m/z 622) as 1-stearoyl-2-(5-oxovaleryl)-sn-glycero-3-phosphocholine by ESIMS. Oxidized SAPC (1.6 mg) was separated by RP-HPLC. The fraction containing compound 3 was dried and dissolved in $80 \% \mathrm{MeOH}$ in $0.5 \mathrm{mM}$ ammonium acetate. Analysis by positive ion ESI-MS followed directly. The molecular structure of compound 3 is also presented. 

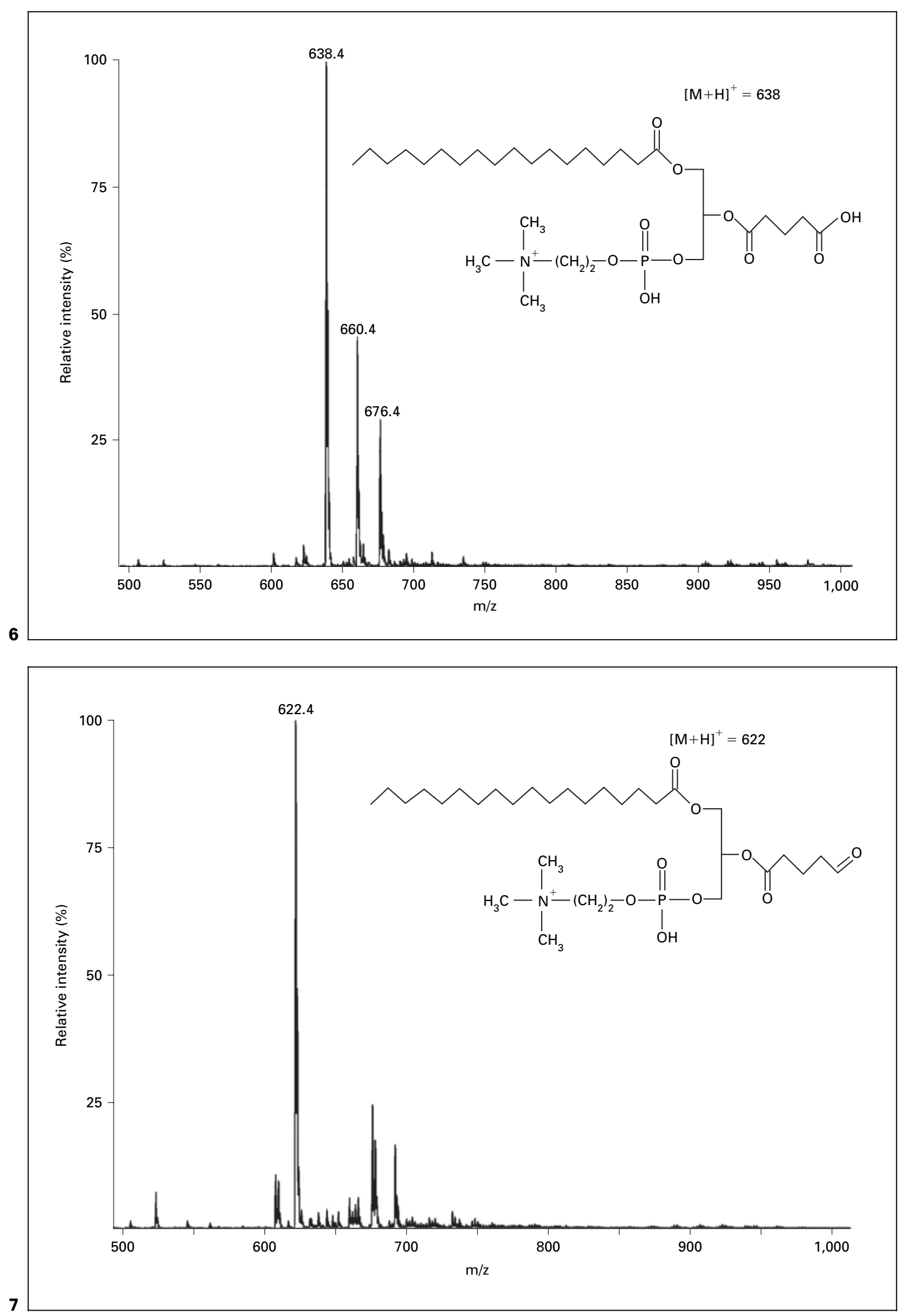


\section{Discussion}

Each of the three major oxidation products of 1-acylPC, SAzPC, SGPC and SOVPC, induced shape change in human platelets, which is the initial step of platelet activation. The potency of the three compounds was similar. Platelet activation induced by SAzPC, SGPC and SOVPC was not mediated by stimulation of the PAF receptor, LPA receptor or $\mathrm{TxA}_{2}$ receptor. Unlike PAF, these compounds did not increase $\left[\mathrm{Ca}^{2+}\right]_{\mathrm{i}}$ in platelets, further demonstrating that they activate platelets by a pathway distinct from PAF. These observations indicate that oxidation of the major phospholipid of LDL, 1-acyl-2-acyl-snglycero-phosphocholine, leads to the formation of distinct phospholipids fragmented at the $s n-2$ position that activate platelets through as yet unknown mechanisms.

Generation of SOVPC and SGPC by oxidation of authentic 1-acyl-PC has been reported previously [19, 23], and it has been found that they stimulate monocyte endothelial cell interaction. This report now demonstrates that these products derived from oxidation of 1-acyl-2-acyl-snglycero-phosphocholine do also activate human platelets. Chemically synthesized PC with short-chain fatty-acid derivatives at the $s n-2$ position has earlier been reported to stimulate serotonin secretion from rabbit platelets and aggregation of human platelets [33]. The most active compounds were PAF-like 1-O-hexadecyl-2-acyl-sn-glycerophosphocholine derivatives. Among the 1-acyl-derivatives, 1-palmitoyl-2-glutaroyl-PC, which is structurally similar to SGPC identified in our study, stimulated serotonin secretion from rabbit platelets that was sensitive to PAF receptor antagonists. However, this substance did not stimulate aggregation of human platelets [33]. Very recently, the PAF-like compound 1-O-hexadecyl-2-(5oxovaleroyl)-sn-glycero-phosphocholine has been identified in human atheroma and found to stimulate aggregation of rabbit platelets through activation of the PAF receptor [15]. In contrast, the corresponding 1-acyl compound, 1-palmitoyl-2-(5-oxovaleroyl)-sn-glycero-phosphocholine (POVPC), induced only shape change that was not suppressed by PAF receptor antagonists [15]. POVPC is structurally almost identical to SOVPC identified in our study, which induced shape change in human platelets independent from the activation of the PAF receptor. Formation of SAzPC has been detected after oxidation of 1-alkyl-PC [18, 34]; however, based on our knowledge, the stimulating effects of SazPC, or a structurally similar substance, on platelet activation have not yet been reported.
Platelet activation by PAF or structurally similar phospholipids through the PAF receptor is an important event in inflammatory and thrombotic conditions. The PAF receptor is highly specific for phospholipids with the following structural characteristics: an $s n-1$ ether bond, an $s n-2$ acetyl residue and a choline head group [35, 36]. This preference excludes activation of the PAF receptor by several $s n-1$ acyl phosphocholines as compared to their $s n-1$ alkyl analogues $[15,17]$. Similarly, we found that the $s n-1$ acyl PC derivatives, SOVPC, SOGPC and SazPC, did not stimulate platelet shape change by activation of the PAF receptor. Furthermore, these compounds neither interacted with the lipid phosphatidate receptors Edg- 2 or Edg4 for LPA [37] nor with the SQ 29,548-sensitive receptors for $\mathrm{TxA}_{2}$, which can also be activated by isoprostanes [38]. In addition, it is very unlikely that the oxidized phospholipids induced platelet activation by membrane perturbation or toxic effects since they did not induce changes in free cytosolic calcium concentrations [39] and since stimulation with PAF increased $\left[\mathrm{Ca}^{2+}\right]_{i}$ even after addition of the oxidized phospholipids.

The putative proatherogenic and prothrombotic role of glutaroyl-PC and 5-oxovaleroyl-PC is supported by their detection in oxidized LDL and in human and animal atherosclerotic lesions. The presence of $1-\operatorname{acyl}\left(\mathrm{C}_{16}\right.$ or $\left.\mathrm{C}_{18}\right)-2$ oxovaleroyl-PC has been reported in extensively oxidized LDL and HDL [40], in minimally or mildly oxidized LDL [19] and in human as well as in rabbit atheroma [15, 19]. In addition, 1-acyl $\left(\mathrm{C}_{16}\right.$ or $\left.\mathrm{C}_{18}\right)$-2-glutaroyl-PC has been identified in mildly oxidized LDL and rabbit atherosclerotic lesions [19]. Therefore, the platelet-activating oxidative derivatives of 1-acyl-PC identified in our study, i.e. SOVPC and SGPC, are generated and present in vivo. Platelet activation induced by the compounds identified in these analyses started at concentrations of about $2.5 \mu M$. In previous studies, fragmented diacyl-PC with short oxidized sn-2 residues were found in blood plasma of young healthy adults in concentrations of about $2.5 \mu M$ and increased significantly in elderly patients with coronary heart disease to concentrations of about $4.0 \mu \mathrm{M}$. Measurements during acute smoking revealed concentrations of up to $7 \mu M$ in healthy volunteers [41]. Furthermore, regarding acute plaque rupture, there will be much higher local concentrations of oxidized phospholipids following the release of plaque lipids. Therefore, the phospholipids identified in this study might play a relevant role in platelet activation in vivo.

In summary, the major 1-acyl-PC oxidation products SAzPC, SGPC and SOVPC, were found to induce platelet shape change through a pathway distinct to the activation 
of the receptors for PAF, LPA and TxA . These compounds are likely to participate in platelet activation induced by oxidized LDL, which is present in the circulation of patients with cardiovascular disease or is exposed upon rupture or erosion of atherosclerotic plaques. In concert with their stimulatory effects on monocytes and endothelial cells, these novel phospholipid oxidation products may not only be important mediators in atherogenesis and inflammation, but also in thrombotic processes.

\section{Acknowledgments}

The authors thank Drs. Wolfgang Erl, Markus Bauer, Carolin Corinth, Michaela Retzer and B. Engelmann for helpful discussions and suggestions, and Monika Morbitzer and Barabara Böhlig for expert technical assistance. This study was supported by the Graduate Program 'Vascular Biology in Medicine' of the 'Deutsche Forschungsgemeinschaft' (GRK 438) and the 'August-Lenz-Stiftung'. The results are part of the doctoral thesis of M.S.G. (University of Munich).

\section{References}

1 Berliner JA, Heinecke JW: The role of oxidized lipoproteins in atherogenesis. Free Radic Biol Med 1996;20:707-727.

2 Weidtmann A, Scheithe R, Hrboticky N, Pietsch A, Lorenz R, Siess W: Mildly oxidized LDL induces platelet aggregation through activation of phospholipase $\mathrm{A}_{2}$. Arterioscler Thromb Vasc Biol 1995; 15:1131-1138.

3 Maschberger P, Bauer M, Baumann-Siemons J, Zangl KJ, Negrescu EV, Reininger AJ, Siess W: Mildly oxidized low density lipoprotein rapidly stimulates via activation of the lysophosphatidic acid receptor Src family and Syk tyrosine kinases and $\mathrm{Ca}^{2+}$ influx in human platelets. $\mathrm{J}$ Biol Chem 2000;275:19159-19166.

4 Volf I, Bielek E, Moeslinger T, Koller F, Koller E: Modification of protein moiety of human low density lipoprotein by hypochlorite generates strong platelet agonist. Arterioscler Thromb Vasc Biol 2000;20:2011-2018.

5 Fernandez-Ortiz A, Badimon JJ, Fuster V, Meyer B, Mailhac A, Weng D, Shah PK, Badimon L: Characterization of the relative thrombogenicity of atherosclerotic plaque components: Implications for consequences of plaque rupture. J Am Coll Cardiol 1994;23:15621569.

6 Sevanian A, Bittolo-Bom G, Cazzolato G, Hodis H, Hwang J, Zamburlini A, Maiorino M, Ursini F: LDL is a lipid hydroperoxide-enriched circulating lipoprotein. J Lipid Res 1997;38:419-428.

7 Holvoet P, Vanhaecke J, Janssens S, Van de Werf F, Collen D: Oxidized LDL and malondialdehyde-modified LDL in patients with acute coronary syndromes and stable coronary artery disease. Circulation 1998;98:14871494.

8 Trip MD, Cats VM, van Capelle FJ, Vreeken J: Platelet hyperreactivity and prognosis in survivors of myocardial infarction. N Engl J Med 1990;322:1549-1554.

9 Esterbauer H, Ramos P: Chemistry and pathophysiology of oxidation of LDL. Rev Physiol Biochem Pharmacol 1996;127:31-64.
10 Watson AD, Navab M, Hama SY, Sevanian A, Prescott SM, Stafforini DM, McIntyre TM, Du BN, Fogelman AM, Berliner JA: Effect of platelet activating factor-acetylhydrolase on the formation and action of minimally oxidized low density lipoprotein. J Clin Invest 1995;95:774782.

11 Berliner JA, Territo MC, Sevanian A, Ramin S, Kim JA, Bamshad B, Esterson M, Fogelman AM: Minimally modified low density lipoprotein stimulates monocyte endothelial interactions. J Clin Invest 1990;85:1260-1266.

12 McIntyre TM, Zimmerman GA, Prescott SM: Biologically active oxidized phospholipids. J Biol Chem 1999;274:25189-25192.

13 Berliner JA, Subbanagounder G, Leitinger N, Watson AD, Vora D: Evidence for a role of phospholipid oxidation products in atherogenesis. Trends Cardiovasc Med 2001;11:142147.

14 Siess W, Zangl KJ, Essler M, Bauer M, Brandl R, Corrinth C, Bittman R, Tigyi G, Aepfelbacher M: Lysophosphatidic acid mediates the rapid activation of platelets and endothelial cells by mildly oxidized low density lipoprotein and accumulates in human atherosclerotic lesions. Proc Natl Acad Sci USA 1999;96:69316936.

15 Kamido H, Eguchi H, Ikeda H, Imaizumi T, Yamana K, Hartvigsen K, Ravandi A, Kuksis A: Core aldehydes of alkyl glycerophosphocholines in atheroma induce platelet aggregation and inhibit endothelium-dependent arterial relaxation. J Lipid Res 2002;43:158-166.

16 Tanaka T, Iimori M, Tsukatani H, Tokumura A: Platelet-activating effects of platelet-activating factor-like phospholipids formed by oxidation of phosphatidylcholines containing an sn2-polyunsaturated fatty acyl group. Biochim Biophys Acta 1994;1210:202-208.

17 Marathe GK, Davies SS, Harrison KA, Silva AR, Murphy RC, Castro-Faria-Neto H, Prescott SM, Zimmerman GA, McIntyre TM: Inflammatory platelet-activating factor-like phospholipids in oxidized low density lipoproteins are fragmented alkyl phosphatidylcholines. J Biol Chem 1999;274:28395-28404.
18 Davies SS, Pontsler AV, Marathe GK, Harrison KA, Murphy RC, Hinshaw JC, Prestwich GD, Hilaire AS, Prescott SM, Zimmerman GA, McIntyre TM: Oxidized alkyl phospholipids are specific, high affinity peroxisome proliferator-activated receptor gamma ligands and agonists. J Biol Chem 2001;276:16015-16023.

19 Watson AD, Leitinger N, Navab M, Faull KF, Horkko S, Witztum JL, Palinski W, Schwenke D, Salomon RG, Sha W, Subanagounder G, Fogelman AM, Berliner JA: Structural identification by mass spectrometry of oxidized phospholipids in minimally oxidized low density lipoprotein that induce monocyte/endothelial interactions and evidence for their presence in vivo. J Biol Chem 1997;272:13597-13607.

20 Watson AD, Subbanagounder G, Welsbie DS, Faull KF, Navab M, Jung ME, Fogelman AM, Berliner JA: Structural identification of a novel pro-inflammatory epoxyisoprostane phospholipid in mildly oxidized low density lipoprotein. J Biol Chem 1999;274:24787-24798.

21 Leitinger N, Tyner TR, Oslund L, Rizza C, Subbanagounder G, Lee H, Shih PT, Mackman N, Tigyi G, Territo MC, Berliner JA, Vora DK: Structurally similar oxidized phospholipids differentially regulate endothelial binding of monocytes and neutrophils. Proc Natl Acad Sci USA 1999;96:12010-12015.

22 Bochkov VN, Mechtcheriakova D, Lucerna M, Huber J, Malli R, Graier WF, Hofer E, Binder BR, Leitinger N: Oxidized phospholipids stimulate tissue factor expression in human endothelial cells via activation of ERK/EGR-1 and $\mathrm{Ca}^{(++)} / \mathrm{NFAT}$. Blood 2002;99:199-206.

23 Subbanagounder G, Leitinger N, Schwenke DC, Wong JW, Lee H, Rizza C, Watson AD, Faull KF, Fogelman AM, Berliner JA: Determinants of bioactivity of oxidized phospholipids. Specific oxidized fatty acyl groups at the sn-2 position. Arterioscler Thromb Vasc Biol 2000;20:2248-2254.

24 Bochkov VN, Kadl A, Huber J, Gruber F, Binder BR, Leitinger N: Protective role of phospholipid oxidation products in endotoxin-induced tissue damage. Nature 2002;419:77-81. 
25 Harrison KA, Murphy RC: Isoleukotrienes are biologically active free radical products of lipid peroxidation. J Biol Chem 1995;270:1727317278.

26 Negrescu EV, Luber de Quintana KL, Siess W: Platelet shape change induced by thrombin receptor activation. Rapid stimulation of tyrosine phosphorylation of novel protein substrates through an integrin- and $\mathrm{Ca}^{(2+)}$-independent mechanism. J Biol Chem 1995;270:10571061 .

27 Rasmussen UB, Gachet C, Schlesinger Y, Hanau D, Ohlmann $\mathrm{P}$, von Obberghen-Schilling E, Pouysségur J, Cazenave JP, Pavirani A: A peptide ligand of the human thrombin receptor antagonizes alpha-thrombin and partially activates platelets. J Biol Chem 1993;268:1432214328.

28 Casals-Stenzal J, Muacevic G, Weber K: Pharmacological actions of WEB 2086, a new specific antagonist of platelet activating factor. $\mathbf{J}$ Pharmacol Exp Ther 1987;241:974-981.

29 Bittman R, Swords B, Liliom K, Tigyi G: Inhibitors of lipid phosphatidate receptors: $\mathrm{N}$ Palmitoyl-serine and N-palmitoyl-tyrosine phosphoric acids. J Lipid Res 1996;37:391398.

30 Kattelman EJ, Venton DL, LeBreton GC: Characterization of U46619 binding in unactivated, intact human platelets and determination of binding site affinities of four TXA2/ PGH2 receptor antagonists (13-APA, BM 13.177, ONO 3708 and SQ 29,548). Thromb Res 1986;41:471-481.
31 Kayganich-Harrison KA, Murphy RC: Characterization of chain-shortened oxidized glycerophosphocholine lipids using fast atom bombardment and tandem mass spectrometry. Anal Biochem 1994;221:16-24.

32 Murphy RC: Mass spectrometry of lipids; in Murphy RC (ed): Handbook of Lipid Research. New York, Plenum Press, 1993, vol 7, pp 5792.

33 Kern H, Volk T, Knauer-Schiefer S, Mieth T, Rüstow B, Kox WJ, Schlame M: Stimulation of monocytes and platelets by short-chain phosphatidylcholines with and without terminal carboxyl group. Biochim Biophys Acta 1998; 1394:33-42.

34 Itabe H, Kushi Y, Handa S, Inoue K: Identification of 2-azelaoylphosphatidylcholine as one of the cytotoxic products generated during oxyhemoglobin-induced peroxidation of phosphatidylcholine. Biochim Biophys Acta 1988;962: 8-15.

35 O'Flaherty JT, Salzer WL, Cousart S, McCall CE, Piantadosi C, Surles JR, Hammett MJ, Wykle RL: Platelet-activating factor and analogues: Comparative study with human neutrophils and rabbit platelets. Res Commun Chem Pathol Pharmacol 1983;39:291-309.
36 O'Flaherty JT, Tessner T, Greene T, Redman JR, Wykle RL: Comparison of 1-O-alkyl-, 1-Oalk-1'-enyl- and 1-O-acyl-2-acetyl-sn-glycero-3phosphoethanolamines and -3-phosphocholines as agonists of the platelet-activating factor family. Biochim Biophys Acta 1994;1210:209_ 216.

37 Goetzl EJ, An S: Diversity of cellular receptors and functions for the lysophospholipid growth factors lysophosphatidic acid and sphingosine 1-phosphate. FASEB J 1998;12:1589-1598

38 Kinsella BT, O'Mahony DJ, Fitzgerald GA: The human thromboxane $\mathrm{A}_{2}$ receptor $\alpha$ isoform $\left(\mathrm{TP}_{\alpha}\right)$ functionally couples to the $\mathrm{G}$ proteins $G_{q}$ and $G_{11}$ in vivo and is activated by the isoprostane 8-epi prostaglandin $\mathrm{F}_{2 \alpha}$. J Pharmacol Exp Ther 1997;281:957-964.

39 Kitagawa S, Endo J, Kametani F: Activation of bovine platelets induced by long-chain unsaturated fatty acids at just below their lytic concentrations, and its mechanism. Biochim Biophys Acta 1984;802:17-23.

40 Kamido H, Kuksis A, Marai L, Myher JJ: Lipid ester-bound aldehydes among copper-catalyzed peroxidation products of human plasma lipoproteins. J Lipid Res 1995;36:1876-1886.

41 Frey B, Haupt R, Alms S, Holzmann G, König T, Kern H, Kox W, Rüstow B, Schlame M: Increase in fragmented phosphatidylcholine in blood plasma by oxidative stress. J Lipid Res 2000;41:1145-1153. 